\title{
INFLUENCE OF APPLICATION SITE OF PROVISIONAL CEMENT ON THE MARGINAL ADAPTATION OF PROVISIONAL CROWNS
}

\author{
Mayra CARDOSO ${ }^{1}$, Marcelo Ferreira TORRES ${ }^{2}$, Mariana Ribeiro de Moraes REGO ${ }^{3}$, Luiz Carlos SANTIAGO ${ }^{4}$
}

\begin{abstract}
1- DDS, Substitute Assistant Professor, Department of Prosthodontics and Dental Materials, Dental School, Federal University of Rio de Janeiro, Rio de Janeiro, RJ, Brazil.

2- DDS, Substitute Assistant Professor, Department of Prosthodontics, Dental School, State University of Rio de Janeiro, Rio de Janeiro, RJ, Brazil. 3- DDS, MSC, Assistant Professor, Department of Prosthodontics, Dental School, State University of Rio de Janeiro, Rio de Janeiro, RJ, Brazil. 4- DDS, PhD, Associate Professor, Department of Prosthodontics and Dental Materials, Dental School, Federal University of Rio de Janeiro, Rio de Janeiro, RJ, Brazil.
\end{abstract}

Corresponding address: Dr. Luiz Carlos Santiago - Faculdade de Odontologia - UFRJ - Departamento de Prótese e Materiais Dentários - Rua Professor Rodolpho Paulo Rocco, 325, 2º. Andar, Bloco K, sala 56 - 21941-617 - Rio de Janeiro - RJ Brazil - Phone: $55212562-2029$ - e-mail: profsantiago@bol.com.br

Received: October 5, 2007 - Modification: December 6, 2007 - Accepted: January 28, 2008

\begin{abstract}
I

$I_{n}$ provisional of provisional crowns. Material and Methods: Four different application sites of provisional cement (Temp Bond NE, Kerr Corporation) were used for cementation of provisional crowns on phantom teeth prepared for full crown restorations, performing 4 experimental groups $(n=10)$ : cement applied to all internal surfaces of the crown (CAO); cement applied to all internal surfaces of the crown, except for the occlusal surface (CA); cement applied to the cervical crown margin (CM); and cement applied to the cervical tooth margin (TM). A comparison microscope (Mitutoyo America Corporation) was used to measure the distances between the internal tangents of two circular marks, one made on the provisional crown and one made apical to the tooth preparation margin, in areas corresponding to buccal, lingual, mesial and distal surfaces. Marginal adaptation was determined before and after cementation, with $0.0001-\mathrm{mm}$ accuracy. Data were analyzed statistically by ANOVA and Tukey's test at 5\% significance level. Results: Mean values of marginal opening obtained for each group were: CAO: $145 \mu \mathrm{m}$; CA: $67 \mu \mathrm{m}$; CM: $46 \mu \mathrm{m}$; TM: $34 \mu \mathrm{m}$. CA, CM and TM presented significantly lower marginal openings than CAO $(\mathrm{p}<0.05)$. Conclusion: complete filling of the crown with provisional cement, including the occlusal surface, provided grater marginal discrepancies when compared to the other methods evaluated.
\end{abstract}

Key words: Marginal opening. Provisional crowns. Provisional cement.

\section{INTRODUCTION}

Incomplete seating of crowns after cementation is a wellknown phenomenon and the ensuing complications have been described ${ }^{9}$. An ill-fitting margin may contribute to increase plaque retention and compromise gingival health by causing alterations in gingival microbiota ${ }^{11}$, also leading to cement washout and loss of retention ${ }^{2}$. This phenomenon has been mainly related to the entrapment of cement between the tooth and the restoration, followed by hydrodynamic intracoronal pressure during cementation, preventing complete seating of the restoration ${ }^{6}$. Therefore, the more accurately the restoration fits the prepared tooth, the more difficult it is for cement excess to escape from the inner crown surface ${ }^{3,12}$. It has been shown that a $25-\mu$ m-thick film may produce a marginal gap of $50 \mu \mathrm{m}$ in well-fitting casts ${ }^{8}$.

Several methods have been suggested to improve the seating of crowns after cementation based on the release of hydrodynamic pressure of cementation. These techniques rely on venting or internal relief of the restoration ${ }^{2,4,5,7,10,11}$. Nevertheless, few studies have reported the influence of the amount of cement or of the application site on the marginal adaptation of cemented crowns ${ }^{2,5,11}$.

Therefore, the aim of this study was to evaluate the influence of the application site of provisional cement on the marginal adaptation of provisional crowns and on cement flow to the internal surfaces of restoration. 


\section{MATERIALAND METHODS}

Forty phantom maxillary premolars (Prodens Produtos Odontológicos LTDA, Niterói, RJ, Brazil) were selected for this study. The region corresponding to the roots of the teeth were embedded in type III gypsum (Jon, São Paulo, SP, Brazil) in cylindrical tubes, and the long axes were aligned parallel to tube walls. For standardization of a 6-degree taper, full crown preparations were performed with a \#4138 diamond bur (KGSorensen Ind. e Com. Ltda, Barueri, SP, Brazil) on a straight high-speed turbine coupled to a surveyor with articulated rod (BioArt 1000; BioArt Equipamentos Odontológicos Ltda, São Carlos, SP, Brazil) (Figure 1). In order to standardize the surface roughness, a new diamond bur was used for each preparation. The height of preparations was determined at $4 \mathrm{~mm}$ with aid of a digital caliper (Starret Indústria e Comércio Ltda, Itu, SP, Brazil).

The provisional crowns were prepared directly on the teeth by application of self-curing acrylic resin (Duralay; Reliance Dental Mfg Co, Wort, IL, USA) with a brush. The occlusal surface was finished thick, flat and parallel to the inferior surface of the cylinder tube. Two aligned circular marks were made with self-curing red acrylic resin (Duralay; Reliance Dental Mfg Co, Wort, IL, USA) in each specimen, one on the provisional crown and other apical to the tooth preparation margin, in areas corresponding to buccal, lingual, mesial and distal surfaces (Figure 2). This procedure maintained the relation of the crown to the tooth by indicating its correct seating position (the marks on the crown

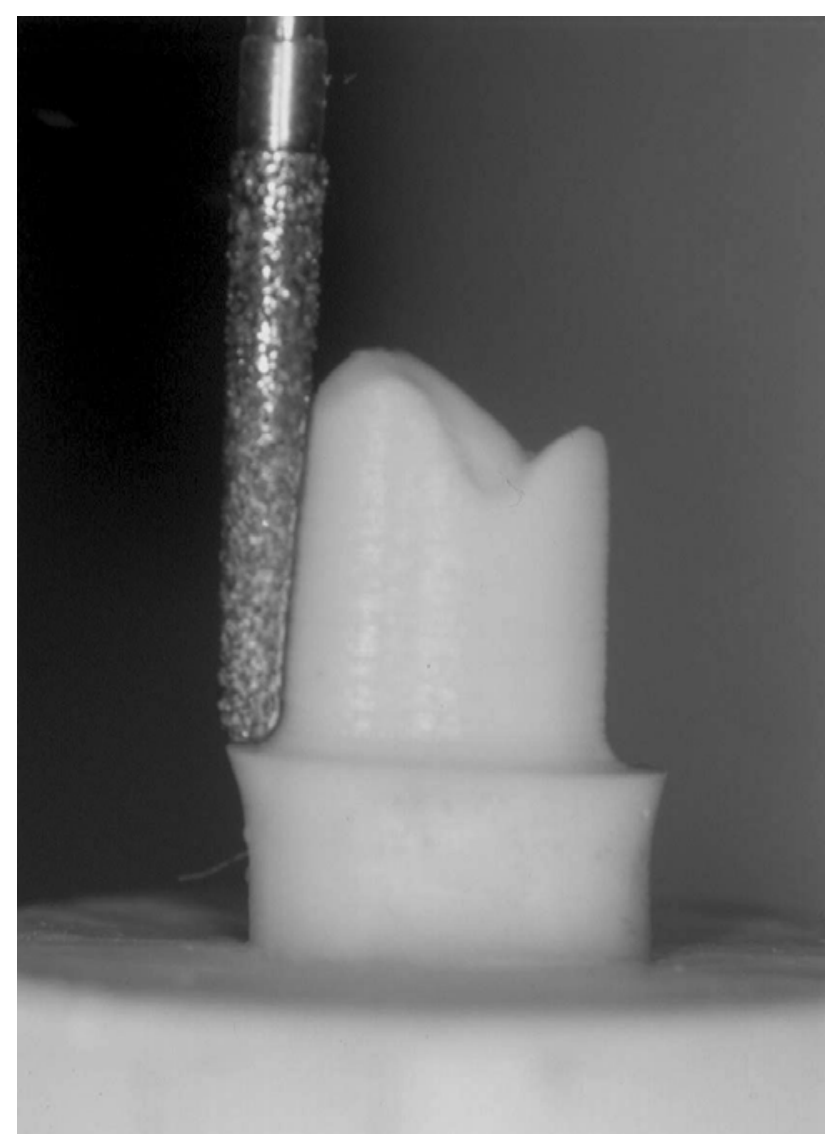

FIGURE 1- Tooth preparation should be aligned to the marks on the tooth), in addition to allowing measurement of marginal opening before and after cementation.

After fabrication of provisional crowns, a 5-kg static load was applied to the occlusal surfaces to allow adequate seating of the restorations. A comparison microscope (Mitutoyo America Corporation, IL, USA) was used to measure the distances between the internal tangents of the
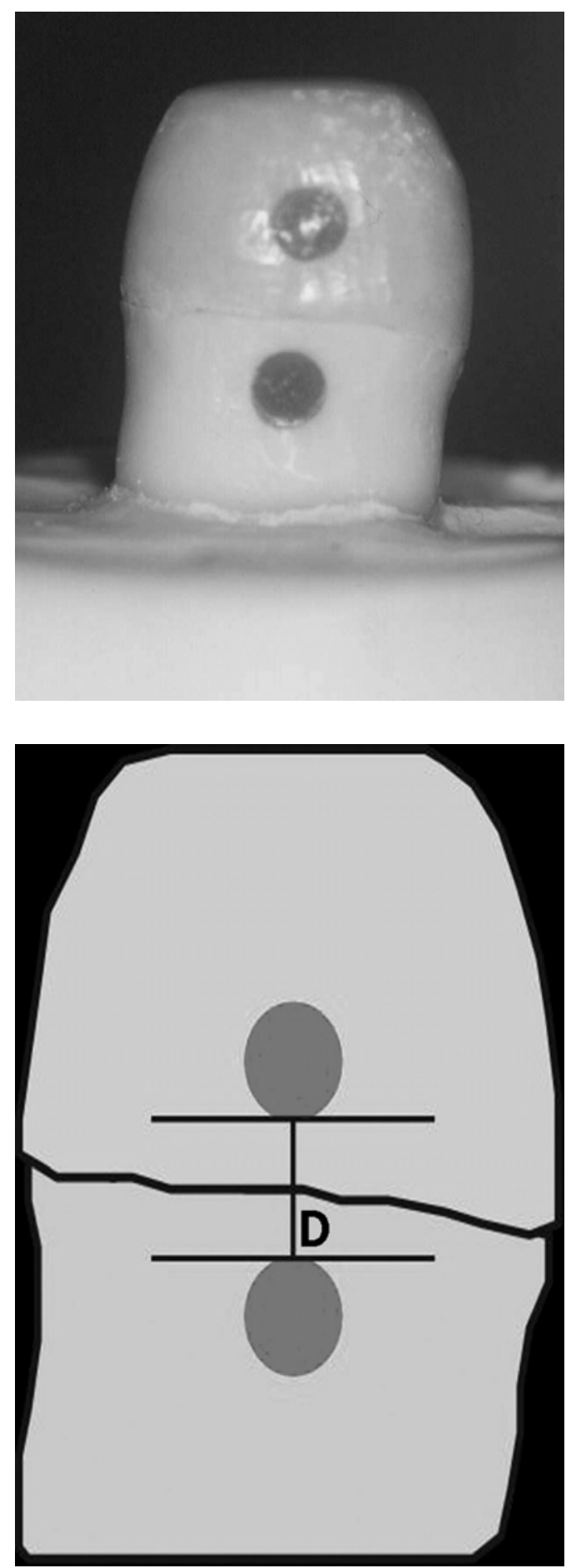

FIGURE 2- Provisional restoration with circular marks (upper panel). Marginal openings obtained before and after cementation were achieved by the distance (D) between the internal tangents of the two circular marks (lower panel) 

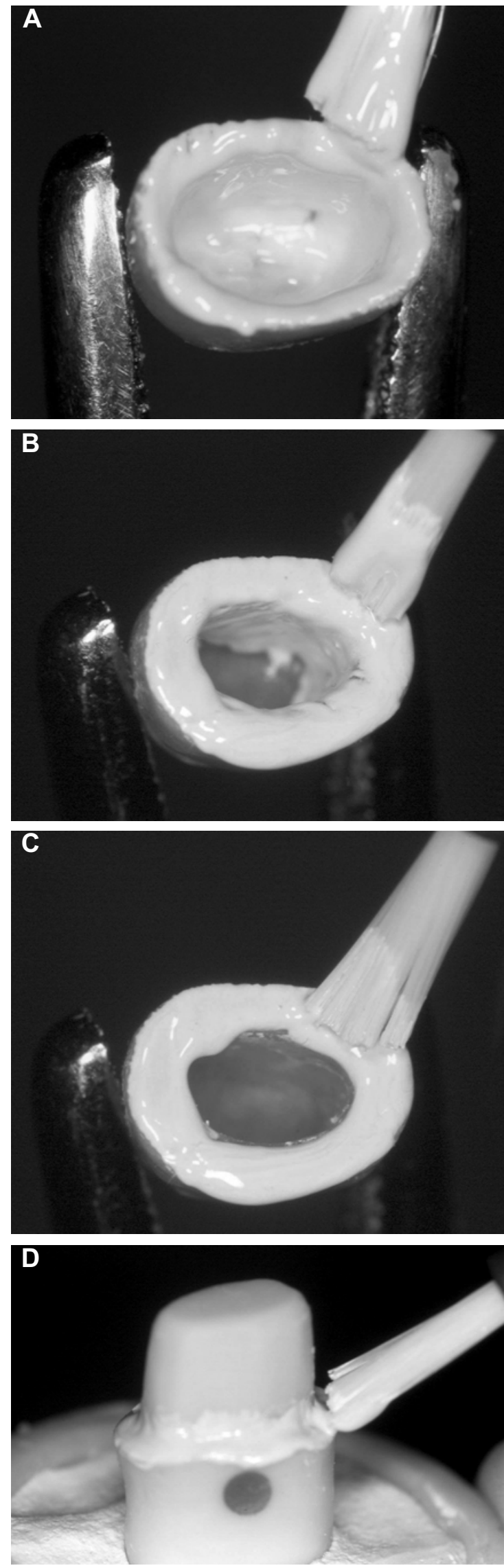

FIGURE 3- Different application sites of cement. A: crown, all axial walls and the occlusal surface. B: crown, all axial walls but the occlusal surface. C: cervical crown margin only. D: cervical tooth margin only two circular marks, determining the pre-cementation marginal opening with $0.0001-\mathrm{mm}$ accuracy (Figure 2). Three measurements were made for each specimen at each tooth surface (buccal, lingual, mesial and distal) and the mean value of these measurements was calculated. The 40 prepared teeth were randomly assigned to 4 groups $(n=10)$ (Figure 3$)$.

A provisional cement (Temp Bond NE; Kerr Corporation, Orange, CA, USA), mixed according to the manufacturer's instructions, was used for cementation of crowns. An amount of $0.2 \mathrm{~mL}$ of the provisional cement (controlled with aid of an insulin syringe) was applied to each crown with a brush. The crowns were seated on the prepared teeth under finger pressure followed by a 5-kg static load until cement setting. Excess cement was removed after cementation for all crowns.

In group $\mathrm{CAO}$, the cement was applied to the inner surface of the crown, comprehending all axial walls and the occlusal surface. The same sites received the cement in group $\mathrm{CA}$, except for the occlusal surface. In group $\mathrm{CM}$, the cement was applied only to the cervical crown margin, and in group TM the cement was applied to the cervical margin of the prepared teeth.

The same procedures adopted for pre-cementation measurements were accomplished to determine postcementation marginal opening. Again, three measurements were made for each specimen in all tooth surfaces (buccal, lingual, mesial and distal) and the mean values were calculated. After post-cementation measurement, the crowns were removed to allow visual evaluation of cement flow on the internal surfaces of restorations.

The marginal discrepancies produced by cementation procedures were determined by the difference between preand post-cementation measurements. Data were analyzed statistically by ANOVA and Tukey's tests at the 5\% significance level.

\section{RESULTS}

Mean values for marginal opening were as follows: CAO: $144.8 \mu \mathrm{m}(\mathrm{SD}=72.6)$; $\mathrm{CA}: 67.2 \mu \mathrm{m}(\mathrm{SD}=21.0)$; $\mathrm{CM}: 45.9 \mu \mathrm{m}$ $(\mathrm{SD}=27.0)$; TM: $34.3 \mu \mathrm{m}(\mathrm{SD}=29.2)($ Table 1$) . \mathrm{CM}$ and TM

TABLE 1- Mean values of marginal discrepancy (in $\mu \mathrm{m}$ ) and standard deviation (SD) for each cementation technique

\begin{tabular}{cll}
\hline Group & MD & SD \\
\hline CAO & 144.8 & 72.6 \\
CA & 67.2 & 21.0 \\
CM & 45.9 & 27.0 \\
TM & 34.3 & 29.2 \\
\hline
\end{tabular}

CAO: crown, all axial walls and the occlusal surface. CA: crown, all axial walls but the occlusal surface. CM: cervical crown margin only. TM: cervical tooth margin only. Groups connected by a vertical line were not statistically different $(\alpha=0.05)$. 
TABLE 2-Analysis of variance

\begin{tabular}{llllll}
\hline $\begin{array}{l}\text { Source } \\
\text { of Variation }\end{array}$ & $\begin{array}{l}\text { Sum of } \\
\text { squares }\end{array}$ & $\begin{array}{l}\text { Degrees of } \\
\text { freedom }\end{array}$ & Mean square & F value & P value \\
\hline Between groups & 74209.700000 & 3 & 24736.566666 & 13.56332 \\
Residue & 65656.200000 & 36 & 1823.7833333 & 0.00000 \\
\hline
\end{tabular}

presented significantly lower marginal openings compared to CAO and CA $(\mathrm{p}<0.05)$. No statistically significant difference was found between CA, CM and TM $(\mathrm{p}>0.05)$ (Table 2).

During visual evaluation of cement flow, it was found that only in group TM the cement did not reach the internal occlusal surface of the restoration, and this occurred in $100 \%$ of the specimens in this group. In the other groups, all crowns were completely filled with the cement.

\section{DISCUSSION}

Several techniques have been described in order to improve the marginal fit of complete crowns after cementation. These include venting or internal relief of the restoration. Yet, it may generate undesirable consequences, such as problems in restoring the vent or loss of retention.

In this study, different application sites of the cement were tested, seeking for the best marginal adaptation after cementation, without the need for venting or restoration internal relief. According to the American Dental Association ${ }^{1}$, the maximum film thickness for class I cements is $25 \mu \mathrm{m}$. Within the limits of this in vitro study, it was found that when the provisional cement was applied only to the cervical margins of the prepared tooth, lower marginal discrepancies were obtained $(34.3 \mu \mathrm{m})$. On the other hand, considerably larger marginal discrepancies were observed when the cement was applied to the internal surfaces of the crown, including the occlusal surfaces $(144.8 \mu \mathrm{m})$, with a high standard deviation, which might be due to the amount of cement applied, as reported elsewhere ${ }^{5,11}$. These authors found that smaller amounts of cement promoted better fit of the restoration.

The results of this study are also in accordance with the findings of Assif, et al. ${ }^{2}$, who evaluated the effect of the site of application of zinc phosphate cement on the marginal adaptation of crowns and found that the preferred method is to apply the cement to the margin of the prepared tooth. These authors also observed that, if applied to the crown, the cement layer should be limited to the crown margin.

Despite the good results obtained in this study with application of cement only to the margin of the prepared tooth, it should be mentioned that this was the only technique in which the cement did not flow to all internal surfaces of the restoration, which could reduce crown retention. The marginal discrepancy values obtained when the cement was applied to the internal surfaces of the crown except for the occlusal surface, or only to the cervical crown margin, were not statistically different from those obtained by cement application to tooth margin alone. Moreover, with $\mathrm{CA}$ and $\mathrm{CM}$ techniques, the cement flowed to all internal surfaces of the restoration, including the occlusal surface. Therefore, the technique of cement application to the crown margin seems to be a good technique from a clinical standpoint, since it provides adequate fit with complete filling of spaces between the internal crown walls and the prepared tooth, with a thinner cement film, as proposed by Ishikiriama, et al. ${ }^{5}$.

\section{CONCLUSION}

Within the limitations of this study, the following conclusion may be drawn: 1. Better marginal fit was achieved after cementation of provisional crown restorations when the cement was applied to the cervical margin of the prepared tooth, to the cervical crown margin or to the internal surfaces of the provisional crown, except for the occlusal surface; 2 . Visual inspection of cement flow, showed that all crowns were completely filled with cement, except for those of group TM (cement applied to the cervical tooth margins), in which the cement did not reach the internal occlusal surface of the restoration.

\section{REFERENCES}

1- American Dental Association. Guide to dental materials and devices. $8^{\text {th }}$ ed. Chicago: The Institution; 1976. p.137-8.

2- Assif D, Rimer Y. The flow of zinc phosphate cement under a full crown coverage restoration and its effect on marginal adaptation according to the location of cement application. Quintessence Int. $1987 ; 18: 765-74$

3- Dimashkieh MR, Davies EH, Fraunhofer JA. Measurement of the cement film thickness beneath full crown restorations. Brit Dent J. $1974 ; 137: 281-4$.

4- Eames WB, O’Neal SJ, Monteiro J, Miller C, Roan JD Jr, Cohen KS. Techniques to improve the seating of castings. J Am Dent Assoc. 1978;96:432-7.

5- Ishikiriama A, Oliveira JF, Vieira DF, Mondelli J. Influence of some factors on the fit of cemented crowns. J Prosthet Dent. 1981;45:400-4.

6- Jorgensen KD. Factors affecting the film thickness of phosphate cements. Acta Odontol Scand. 1960;18:479-90. 
7- Moore JA, Barghi N, Brukl CE, Kaiser DA. Marginal distortion of cast restorations induced by cementation. J Prosthet Dent. $1985 ; 54: 336-40$

8- Ostlund LE. Cavit design and mathematics: Their effect on gaps at the margins of cast restorations. Oper Dent. 1985;10:122-37.

9- Pilo R, Cardash HS. In vitro retrospective study of cement thickness under crowns. J Prosthet Dent. 1998;79:621-5.

10- Scrabeck JG, Eames WB, Noonan JE. A method for uniform seating pressure on castings during cementation. J Prosthet Dent. $1987 ; 57: 537-9$

11- Tan K, Ibbetson R. The effect of cement volume on crown seating. Int J Prosthodont. 1996;9:445-51.

12- Wang CJ, Millstein PL, Nathanson D. Effects of cement, cement space, marginal design, seating aid materials, and seating force on crown cementation. J Prosthet Dent. 1992;67:786-90. 